\section{(อ) \\ OPEN ACCESS}

\title{
Internal herniation following laparoscopic pancreatoduodenectomy
}

\author{
David Jan Brinkman 다, ${ }^{1}$ Jony Van Hilst, ${ }^{2}$ Misha D Luyer ${ }^{1}$
}

${ }^{1}$ Department of Surgery, Catharina Hospital, Eindhoven, The Netherlands

${ }^{2}$ Department of Surgery, Amsterdam UMC - Locatie AMC Amsterdam, The Netherlands

\section{Correspondence to} Mr David Jan Brinkman; daan.brinkman@ catharinaziekenhuis.nl

Accepted 15 December 2019

\section{SUMMARY}

Laparoscopic pancreatoduodenectomy (LPD) is increasingly performed worldwide as an alternative to the open conventional method, with the aim of advancing recovery. Because of its recent introduction, little is known about late surgical complications from this procedure. Here, we describe a case of a 76-yearold woman who underwent LPD with end-to-side gastrojejunostomy and presented with pain in the right upper quadrant of the abdomen 6 months thereafter. CT showed signs of an internal herniation. Elective diagnostic laparoscopy demonstrated a hernia of the efferent loop in Petersen's space. The loop was repositioned and Petersen's space was closed. The patient was discharged on the same day. Apart from a short readmission for nausea and vomiting, which were managed conservatively, the patient recovered without any further complications. Internal herniation should be considered in patients with abdominal complaints following LPD.

\section{BACKGROUND}

Laparoscopic pancreatoduodenectomy (LPD) is increasingly conducted over the last decade and is, when performed in expert centres, possibly associated with a decreased length of stay and reduced intraoperative blood loss. ${ }^{1}$ Research on this novel procedure is mostly focused on safety and complications early in the postoperative period, but data on long-term surgical outcome is limited. The current report describes a patient with pain in the right upper abdomen caused by a Petersen's internal herniation following LPD.

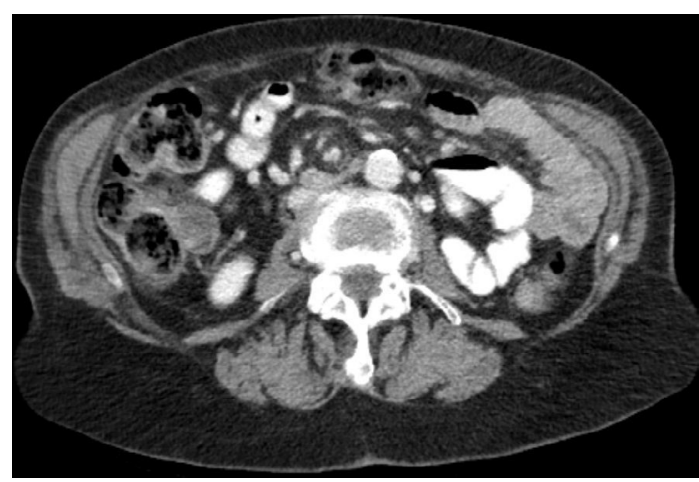

Figure $1 \mathrm{CT}$ abdomen showing swirl of the superior mesenteric artery and vein.

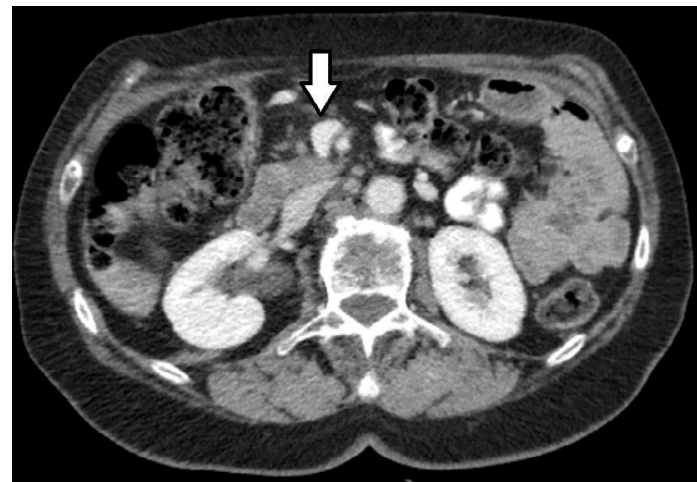

Figure $2 \mathrm{CT}$ abdomen showing congestion of the superior mesenteric vein (arrow).

\section{CASE PRESENTATION}

A 76-year-old woman with a history of rheumatoid arthritis, left hip replacement, laparoscopic cholecystectomy and hysterectomy presented with jaundice, abdominal pain and weight loss at our

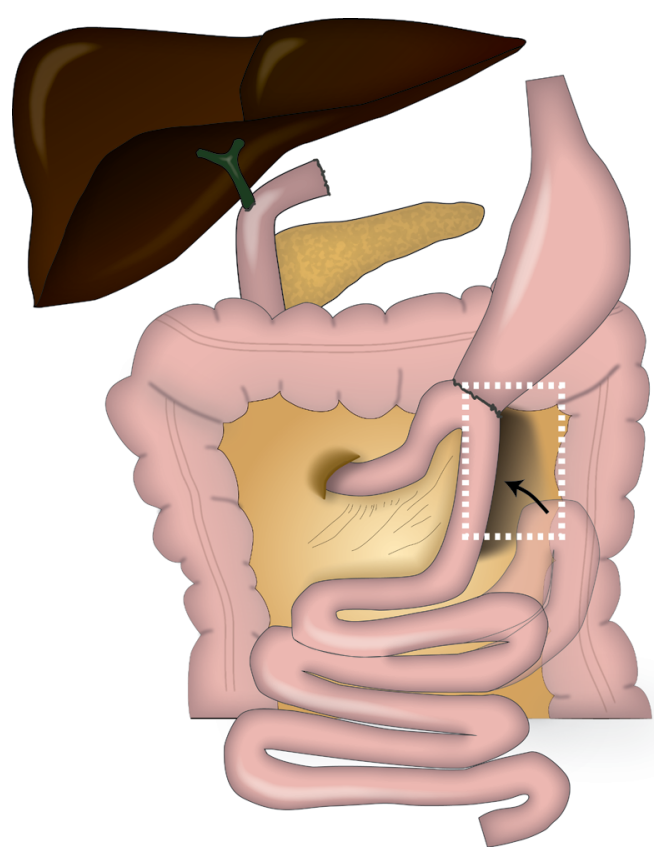

Figure 3 Schematic presentation of this case. Following laparoscopic pancreatoduodenectomy, with the creation of a hepaticojejunostomy, pancreaticojejunostomy and gastrojejunostomy, an intestinal loop has herniated (arrow) in the space posterior to the gastrojejunostomy (Petersen's space, highlighted in white box). Image created by Anne Ten Hove and David Brinkman. 


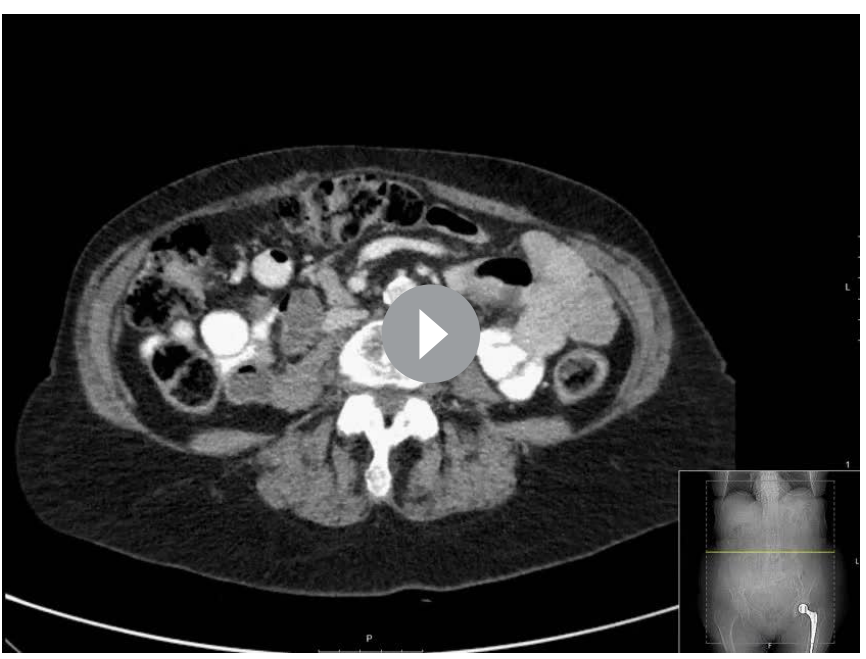

Video 1. CT abdomen showing swirl of the superior mesenteric artery and vein and torsion of the small bowel.

hospital. Endoscopic retrograde cholangiopancreatography revealed a stenosis in the common bile duct and subsequent biopsies ascertained adenocarcinoma. CT did not show any signs of metastases, after which the patient underwent an LPD with end-to-side gastrojejunostomy. No perioperative complications occurred and the patient was discharged 9 days after surgery. After 6 months during a regular check-up, the patient was experiencing recurrent abdominal pain without nausea and dysphagia.

\section{INVESTIGATIONS}

An abdominal contrast CT (video 1) showed swirl of superior mesenteric artery and vein (figure 1), torsion of small bowel and venous congestion (figure 2 ).

\section{TREATMENT}

An elective laparoscopy was planned 2 weeks following the CT scan since no acute symptoms were present. During laparoscopy, a herniation of the efferent loop in Petersen's space was observed (figure 3). No bowel ischaemia was present. The hernia was repaired and the mesenteric defect was closed with sutures afterwards (figure 4).

\section{OUTCOME AND FOLLOW-UP}

The patient recovered quickly and was discharged on the same day as the operation. After 3 days, the patient was readmitted because of nausea and vomiting, which was most likely related to gastroparesis. Due to effective conservative treatment with a

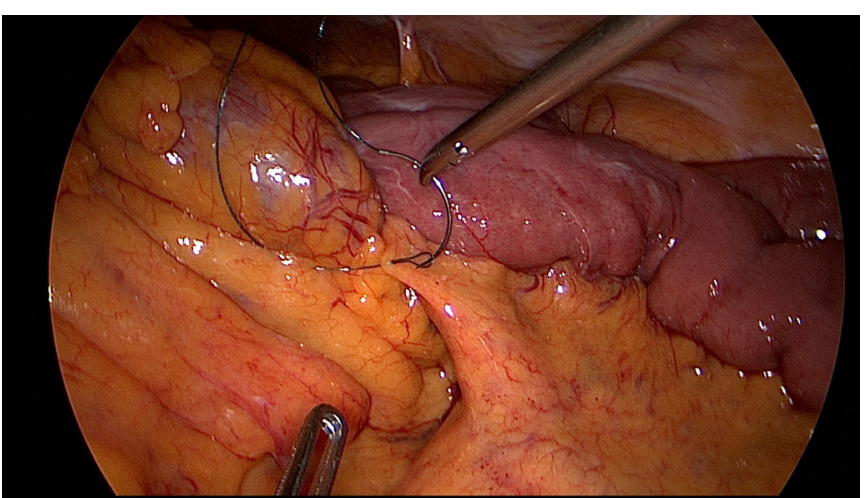

Figure 4 Closure of the mesenteric defect during laparoscopy.

\section{Learning points}

- Internal herniation should be considered in patients presenting with abdominal complaints following laparoscopic pancreatoduodenectomy (LPD).

- Patients with an internal herniation do not always present with nausea and vomiting.

- Closing of mesenteric defects during the initial surgical procedure might prevent internal herniation following LPD.

nasogastric tube and enemas, the patient recovered and could be discharged after 3 days.

\section{DISCUSSION}

Pancreatoduodenectomy remains the only curative treatment for (pre)malignant tumours in the periampullary region. As in other types of abdominal surgery, a laparoscopic approach could improve recovery and possibly reduce length of stay. ${ }^{1}$ Due to its recent introduction, studies have focused on short-term surgical outcome, while little is known on late complications following LPD.

Internal herniation is an occasional but potentially lifethreatening complication following abdominal surgery with an incidence between $1.1 \%$ and $6.1 \%$ after laparoscopic gastric bypass surgery. ${ }^{2-4}$ Although internal herniation is predominantly described in bariatric surgery, it is rarely seen following (open) pancreatoduodenectomy. In fact, only two studies have reported a case of internal herniation following open pancreatoduodenectomy. ${ }^{5}{ }^{6}$ For robotic-assisted pancreatoduodenectomy, a recent study found internal herniation in 5 out of 192 cases $(2.6 \%)$. Patients in this study presented with symptoms such as nausea, vomiting or merely vague abdominal pain. ${ }^{7}$ Thus far, no cases of internal herniation have been reported following LPD, but a similar incidence of internal herniation could be expected as observed after robotic surgery.

Closure of the mesenteric defect has been proposed as a method to prevent internal herniation. Indeed, a meta-analysis demonstrated that closure of the defects was associated with a decreased incidence of internal herniation following laparoscopic bypass surgery, which was confirmed in a randomised controlled trial. $^{89}$ Closure also appears to have a preventive effect in robotic-assisted pancreatoduodenectomy. ${ }^{7}$ Using surgical videos, Qin et al found the incidence of internal herniation to be $0 \%$ after closure of the mesenteric defect $(0 / 31)$ compared with $63 \%$ $(5 / 8)$ when the mesenteric defect was left untreated. Although it could provoke early small bowel obstruction, closure of the mesenteric defect should be considered during LPD to prevent internal herniation.

In summary, this report describes an internal herniation following LPD, which was successfully treated laparoscopically by repositioning the hernia and closure of the defect in Petersen's space. This diagnosis should be considered in patients with abdominal complaints following LPD.

Contributors MDL has treated the patient. DJB drafted the manuscript. DJB, JVH and MDL critically revised the manuscript. All authors approved the final version of the manuscript.

Funding The authors have not declared a specific grant for this research from any funding agency in the public, commercial or not-for-profit sectors.

Competing interests None declared.

Patient consent for publication Obtained

Provenance and peer review Not commissioned; externally peer reviewed.

Brinkman DJ, et al. BMJ Case Rep 2020;13:e232475. doi:10.1136/bcr-2019-232475 
Open access This is an open access article distributed in accordance with the Creative Commons Attribution Non Commercial (CC BY-NC 4.0) license, which permits others to distribute, remix, adapt, build upon this work non-commercially, and license their derivative works on different terms, provided the original work is properly cited and the use is non-commercial. See: http://creativecommons.org/ licenses/by-nc/4.0/.

\section{ORCID iD}

David Jan Brinkman http://orcid.org/0000-0003-1862-9256

\section{REFERENCES}

1 de Rooij T, Lu MZ, Steen MW, et al. Minimally invasive versus open pancreatoduodenectomy: systematic review and meta-analysis of comparative cohort and registry studies. Ann Surg 2016;264:257-67.

2 Ederveen JC, van Berckel MMG, Nienhuijs SW, et al. Predictive value of abdominal CT in evaluating internal herniation after bariatric laparoscopic Roux-en-Y gastric bypass. $\mathrm{Br} J$ Surg 2018;105:1623-9.
3 Rausa E, Bonavina L, Asti E, et al. Rate of death and complications in laparoscopic and open Roux-en-Y gastric bypass. A meta-analysis and meta-regression analysis on 69,494 patients. Obes Surg 2016;26:1956-63.

4 Al-Mansour MR, Mundy R, Canoy JM, et al. Internal hernia after laparoscopic antecolic Roux-en-Y gastric bypass. Obes Surg 2015;25:2106-11.

5 Yamanaka T, Araki K, Hagiwara K, et al. Internal hernia into the Treitz fossa after pancreaticoduodenectomy. Case Rep Gastroenterol 2017;11:651-4.

6 Patel P, Patel N, Atia A, et al. Massive gastric dilatation secondary to internal hernia obstructing the biliary intestinal limb of Whipple procedure. ACG Case Rep J 2013;1.

7 Qin K, Wu Z, Jin J, et al. Internal hernia following robotic assisted pancreaticoduodenectomy. Med Sci Monit 2018;24:2287-93.

8 Geubbels N, Lijftogt N, Fiocco M, et al. Meta-Analysis of internal herniation after gastric bypass surgery. Br J Surg 2015;102:451-60.

9 Stenberg E, Szabo E, Ågren G, et al. Closure of mesenteric defects in laparoscopic gastric bypass: a multicentre, randomised, parallel, open-label trial. Lancet 2016;387:1397-404.

Copyright 2020 BMJ Publishing Group. All rights reserved. For permission to reuse any of this content visit https://www.bmj.com/company/products-services/rights-and-licensing/permissions/

BMJ Case Report Fellows may re-use this article for personal use and teaching without any further permission.

Become a Fellow of BMJ Case Reports today and you can:

- Submit as many cases as you like

- Enjoy fast sympathetic peer review and rapid publication of accepted articles

- Access all the published articles

- Re-use any of the published material for personal use and teaching without further permission

Customer Service

If you have any further queries about your subscription, please contact our customer services team on +44 (0) 2071111105 or via email at support@bmj.com.

Visit casereports.bmj.com for more articles like this and to become a Fellow 